\title{
Severe acute respiratory distress syndrome caused by unintentional sewing machine lubricant ingestion: A case report
}

\author{
Sunil Kishore, Sudha Chandelia1, Neha Patharia, Swarnim
}
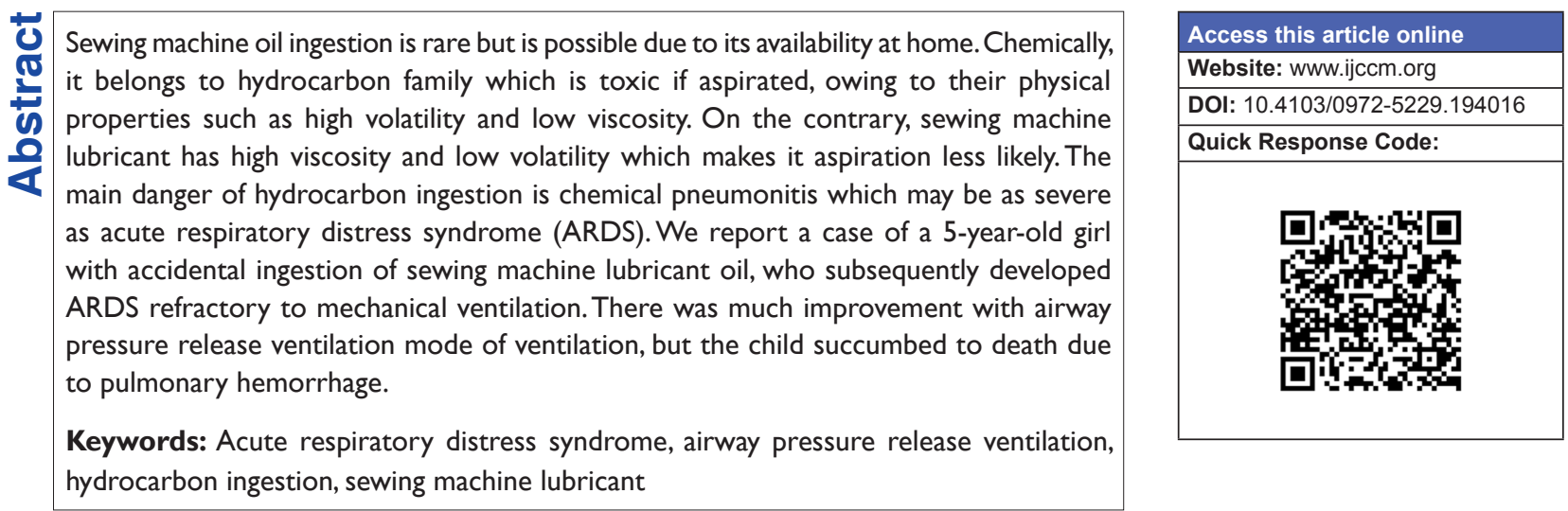

\section{Introduction}

Sewing machine lubricant is a type of hydrocarbon which is easily available at home and thus is a potential source of poisoning. ${ }^{[1]}$ It is different from other domestic hydrocarbon products by the fact that it has got relatively high viscosity and low volatility..$^{[2]}$ These properties make its aspiration potential and toxicity low if ingested. We report a case of a 5-year-old girl with accidental sewing machine oil ingestion who developed severe toxicity with subsequent hypoxemic respiratory failure developing acute respiratory distress syndrome (ARDS). The mechanism of injury results from direct toxicity to pulmonary parenchyma and disruption of the surfactant layer. ${ }^{[3]}$ To the best of our knowledge, severe ARDS from sewing machine oil ingestion has not been reported previously.

\section{From:}

Departments of Pediatric and ${ }^{1}$ Pediatric Critical Care, PGIMER and

Associated Dr. Ram Manohar Lohia Hospital, New Delhi, India

\section{Correspondence:}

Dr. Sudha Chandelia, Room No. 403, Academic Building, PGIMER, Dr. Ram Manohar Lohia Hospital, New Delhi - 110 001, India.

E-mail: sudhach83@ rediffmail.com

\section{Case Report}

A 5-year-old girl came to our emergency room with 4-5 episodes of nonbilious vomiting, fever, and fast breathing for 1 day. She was irritable (Glasgow Coma Scale-9) and had severe respiratory distress. She had a heart rate-126/min, respiratory rate- $60 / \mathrm{min}$, subcostal and intercostal retractions, blood pressure- $94 / 60 \mathrm{mmHg}$, $\mathrm{SpO}_{2}-78 \%$ on room air and $86 \%$ on oxygen flow $51 / \mathrm{min}$. There were bilateral crepts in chest and a soft liver measuring $3 \mathrm{~cm}$ in abdomen. She was immediately stabilized with oxygen and fluids and was shifted to Pediatric Intensive Care Unit in view of increased work of breathing and hypoxemia. Antibiotics were started as total leukocyte count was $24,500 / \mathrm{mm}^{3}$ (95\% neutrophils).

This is an open access article distributed under the terms of the Creative Commons Attribution-NonCommercial-ShareAlike 3.0 License, which allows others to remix, tweak, and build upon the work non-commercially, as long as the author is credited and the new creations are licensed under the identical terms.

For reprints contact: reprints@ @edknow.com

How to cite this article: Kishore S, Chandelia S, Patharia N, Swarnim. Severe acute respiratory distress syndrome caused by unintentional sewing machine lubricant ingestion: A case report. Indian J Crit Care Med 2016;20:671-3. 
Liver enzymes were raised (SGPT/SGOT-2316/1039), urea/creatinine were 40/0.7; serum electrolyte were normal. Parents related that 6 days earlier, she had drunk sewing machine oil accidentally, kept in a drinking water bottle. Followed this she had 4-5 episodes of vomiting and treated on outpatient department basis for 2 days. On the $3^{\text {rd }}$ day, she deteriorated and admitted to another hospital but her condition got worse over 4 days in the form of respiratory distress when she was referred to us. We tried indigenous continuous positive airway pressure which failed to maintain her oxygenation as evidenced by $\mathrm{PaO}_{2} 48.9, \mathrm{SpO}_{2} 87 \%\left(\mathrm{PaO}_{2} / \mathrm{FiO}_{2}\right.$ ratio-49). We put her on pressure control ventilation $(\mathrm{PCV})$ with initial settings peak inspiratory pressure-22, positive end-expiratory pressure (PEEP)-6 gradually increased to $16 \mathrm{~cm} \mathrm{H}_{2} \mathrm{O}$, respiratory rate-26, $\mathrm{FIO}_{2}-100 \%$. The patient needed midazolam infusion up to $8 \mu \mathrm{g} / \mathrm{kg} / \mathrm{min}$ due to asynchrony. Chest X-ray showed diffuse opacity over bilateral lung field suggestive of ARDS [Figure 1]. Switch to volume controlled ventilation resulted in rapid worsening necessitating return to PCV. She was also kept in prone position for $16 \mathrm{~h}$. Recruitment maneuvers were performed were performed after every endotracheal tube suction procedure. Intravenous methylprednisolone was also started for refractory hypoxemia. Her saturations were now $77 \%$ with a $\mathrm{PO}_{2}-52 \mathrm{mmHg}$. In view of poor response, we shifted her to airway pressure release ventilation (APRV) mode with initial settings ( $P_{\text {high }}$ $30, \mathrm{P}_{\text {low }} 0, \mathrm{~T}_{\text {high }} 4$, and $\mathrm{T}_{\text {low }} 0.3$ ). After $30 \mathrm{~min}$, saturation improved to $87 \%$ and then $97 \%$ after an hour. Arterial blood gas done after $1 \mathrm{~h}$ showed $\mathrm{PO}_{2}-80$ and $\mathrm{PCO}_{2}-58$, PH-7.2. We adjusted settings and PH maintained at 7.27. On APRV mode, the child could continue breathing spontaneously and sedation could be stopped within $6 \mathrm{~h}$. The $\mathrm{FIO}_{2}$ could be decreased to $80 \%$ after $6 \mathrm{~h}$. She maintained saturation above $90 \%$ for more than $40 \mathrm{~h}$ on the APRV mode but again started deteriorating. She

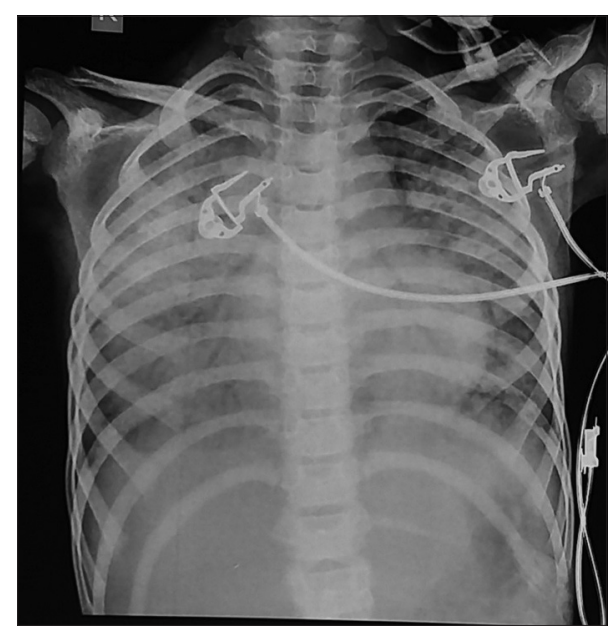

Figure I: Chest X-ray showing ground glass appearance suggestive of acute respiratory distress syndrome developed pulmonary bleeding. Prothrombin time/ international normalized ratio was raised 18/1.7 for which Vitamin $\mathrm{K}$ and fresh frozen plasma were given. This time she was prepared for extracorporeal membrane oxygenation (ECMO). Before this could be instituted she had a bradycardic arrest followed by death.

\section{Discussion}

Unintentional chemical aspiration is a major cause of injuries in children due to their curiosity and adventurous behavior. ${ }^{[4]}$ Sewing machine oil contains a chemically-processed petroleum product, a type of hydrocarbon. Hydrocarbon ingestion represents the third chief cause of poisoning deaths in children $\leq 5$ years of age. ${ }^{[4]}$ Its high aspiration potential is due to its property of volatility and viscosity. Viscosity is measured in saybolt seconds universal (SSU). A SSU of $<45$ correlates with a high potential for aspiration (e.g., gasoline, kerosene), and a SSU >100 indicates a high tendency to resist flow, and therefore, a low potential for aspiration (e.g., lubricants). The toxicity is due to their low surface tension which causes these to spread from upper esophagus to trachea and inhibit surfactant resulting in alveolar collapse and decreased pulmonary compliance. These may also cause direct pulmonary injury, inflammation, edema, and necrosis. Desquamation of pneumocytes and hemorrhage may occur. Symptoms appear immediately or within a few hours. Delayed presentation after $48 \mathrm{~h}$ has been attributed to superimposed bacterial infection. Our patient presented on the $3^{\text {rd }}$ day with ARDS which seems to be purely due to chemical toxicity. She had multiple episodes of vomiting and must have aspirated it. There is no antidote so treatment is mainly supportive with mechanical ventilation. There is no consensus on most effective mode of ventilation. In this case, we saw an improvement in hypoxemia with APRV mode when low tidal volume strategy failed. APRV mode controls peak airway pressure, increases mean airway pressure and hence improves oxygenation. During APRV, alveolar recruitment occurs continuously and thus intermittent recruitment manoeuvres can be avoided which protects the child from derecruitment during maneuvers. Moreover, the patient can breathe spontaneously getting better dependent lung ventilation, improved muscle tone, and decreased requirement of sedation and paralytics. ${ }^{[5]}$ Other methods which could have been used are inhaled nitric oxide (iNO), high-frequency oscillatory ventilation (HFOV) and ECMO. HFOV has been shown to improve outcome in patients of hydrocarbon-induced ARDS by continuously maintaining mean airway pressure above closing pressure which prevents cyclic derecruitment. ${ }^{[6]}$ iNO showed an improved outcome 
in an 18-month-old girl in whom Pressure-regulated volume control ventilation, HFOV, and surfactant failed. ${ }^{[7]}$ In our institution we had neither HFOV nor iNO capability. Exogenous surfactant therapy $(5 \mathrm{ml} / \mathrm{kg})$ is effective as shown in younger patients of age 17 and 19 months but it was not feasible in our patient because of her higher age and weight. ${ }^{[8,9]}$ The role and dose of surfactant need to be defined in older children. ECMO has documented to be useful for recovery of hypoxemia in patients with hydrocarbon ARDS refractory to mechanical ventilation. ${ }^{[10]}$ The role of corticosteroids and antibiotics is limited due to scant data. We could find only one study which was done in dogs in 1972. The researchers induced lung injury by instilling the median lethal dose of kerosene intratracheally. They did not find any benefit of injectable dexamethasone in hydrocarbon aspiration. ${ }^{[1]]}$

Accidental ingestion of hydrocarbons is common because many hydrocarbon products are available as solvents, fuels, cleaning, and lubricating agents at home. Keeping such products in water bottle will increase the chances of their accidental ingestion. Parents and caregivers should be very cautious when keeping such compounds at home. The peculiar point about this case is that respiratory distress developed late. Medical care was not sought until $19 \mathrm{~h}$ after initial exposure. The child mainly had gastrointestinal and hepatotoxicity initially. Delayed respiratory involvement may be due to low aspiration potential of the lubricant owing to a high viscosity. There was nothing mentioned on the container but on searching literature, we found that sewing machine oil has a viscosity of 280 SSU. Chemical pneumonitis due to hydrocarbon ingestion can be very severe and may lead to ARDS refractory to mechanical ventilation. Although we saw marked physiologic improvement with APRV mode of ventilation but further data is required to make any statement on the role of it in such cases.

\section{Financial support and sponsorship}

Nil.

\section{Conflicts of interest}

There are no conflicts of interest.

\section{References}

1. Tormoehlen LM, Tekulve KJ, Nañagas KA. Hydrocarbon toxicity: A review. Clin Toxicol (Phila) 2014;52:479-89.

2. Haas C, Lebas FX, Le Jeunne C, Lowenstein W, Durand H, Hugues FC. Pneumopathies caused by inhalation of hydrocarbons: Apropos of 3 cases. Ann Med Interne (Paris) 2000;151:438-47.

3. Zucker AR, Sznajder JL, Becker CJ, Berger S, Wood LD. The pathophysiology and treatment of canine kerosene pulmonary injury: Effects of plasmapheresis and positive end expiratory pressure. J Crit Care 1989; $4: 184-93$

4. Mowry JB, Spyker DA, Cantilena LR Jr., McMillan N, Ford M. 2013 annual report of the American association of poison control centers' National Poison Data System (NPDS): $31^{\text {st }}$ annual report. Clin Toxicol (Phila) 2014;52:1032-283.

5. Frawley PM, Habashi NM. Airway pressure release ventilation: Theory and practice. AACN Clin Issues 2001;12:234-46.

6. Lee LK, Shannon M, Arnold J. The use of high frequency oscillatory ventilation in hydrocarbon pneumonitis. Int J Med Toxicol 2003;6:10.

7. Patwari PP, Michelson K. Use of inhaled nitric oxide for hydrocarbon aspiration. Chest [Internet]. Elsevier BV; 2005;128:445S-1445S-2. Available from: http://dx.doi.org/10.1378/chest.128.4_ meetingabstracts.445s. [Last accessed on 2016 Aug 31].

8. Horoz OO, Yildizdas D, Yilmaz HL. Surfactant therapy in acute respiratory distress syndrome due to hydrocarbon aspiration. Singapore Med J 2009;50:e130-2.

9. Mastropietro CW, Valentine K. Early administration of intratracheal surfactant (calfactant) after hydrocarbon aspiration. Pediatrics 2011;127:e1600-4.

10. Weber TR, Kountzman B. Extracorporeal membrane oxygenation for nonneonatal pulmonary and multiple-organ failure. J Pediatr Surg 1998;33:1605-9.

11. Steele RW, Conklin RH, Mark HM. Corticosteroids and antibiotics for the treatment of fulminant hydrocarbon aspiration. JAMA 1972;219:1434-7. 